\title{
Reduction Behaviors of Nitric Oxides on Copper-decorated Mesoporous Molecular Sieves
}

\author{
Ki-Sook Cho, Byung-Joo Kim, ${ }^{\dagger}$ Seok Kim, ${ }^{\ddagger}$ Sung-Hyun Kim, and Soo-Jin Park ${ }^{\S}{ }^{*}$ \\ Environment Systems Engineering, Korea University, Seoul 136-701, Korea \\ ${ }^{\dagger}$ Nano Material Research Dept., Jeonju Institute of Machinery and Carbon Composites, Jeonju 561-844, Korea \\ ${ }^{\ddagger}$ Dept. of Chemical and Biochemical Engineering, Pusan National Univ., Pusan 609-735, Korea \\ ${ }^{\S}$ Dept. of Chemistry, Inha Univ., Incheon 402-751, Korea. *E-mail: sjpark@inha.ac.kr \\ Received July 15, 2009, Accepted November 24, 2009
}

\begin{abstract}
In this study, NO reduction behaviors of copper-loaded mesoporous molecular sieves (Cu/MCM-41) have been investigated. The $\mathrm{Cu}$ loading on MCM-41 surfaces was accomplished by a chemical reduction method with different $\mathrm{Cu}$ contents $(5,10,20$, and $40 \%) . \mathrm{N}_{2} / 77 \mathrm{~K}$ adsorption isotherm characteristics, including the specific surface area and pore volume, were studied by BET's equation. NO reduction behaviors were confirmed by a gas chromatography. From the experimental results, the $\mathrm{Cu}$ loading amount on MCM-41 led to the increase of NO reduction efficiency in spite of decreasing the specific surface area of catalysts. This result indicates that highly ordered porous structure in the MCM-41 and the presence of active metal particles lead the synergistical NO reduction reactions due to the increase in adsorption energy of MCM-41 surfaces by the $\mathrm{Cu}$ particles.
\end{abstract}

Key Words: NO reduction, Mesoporous molecular sieve, Textural properties

\section{Introduction}

Air pollution has been aggravated by four developments: increasing traffic, urban growth, rapid economic development, and industrialization. Air pollution threatens the health of human beings and other life on our planet. ${ }^{1}$ Increasingly stringent regulation of air pollution emission requires further investigations on suppressing emission of harmful matters from high temperature industrial processes. It has been long recognized that nitrogen monoxide, NO is one of the harmful air pollutants in the processes. Nitric oxide in the air can convert to nitric acid, which has been implicated in acid rain. Furthermore, both $\mathrm{NO}$ and $\mathrm{NO}_{2}$ participate in ozone layer depletion. Nitric oxide is a small highly diffusible gas and a ubiquitous bioactive molecule. ${ }^{2,3}$

As a thermodynamic perspective, NO is unstable with respect to $\mathrm{O}_{2}$ and $\mathrm{N}_{2}$, although this conversion is very slow at ambient temperatures in the absence of a catalyst because the heat of formation of NO is endothermic. However, the use of internal combustion engines has drastically increased the presence of nitric oxide in the environment. To overcome these problems, some researchers have reported NO reduction technology using metals supported on activated carbons (ACs) or activated carbon fibers (ACFs) by impregnation, metal plating, deposition, and so on. ${ }^{4,5}$

However, porous carbons above mentioned have micropores $(\mathrm{r}<2 \mathrm{~nm})$ richly, meaning that the specific surface area and the pore volume of the support can be severely reduced after metal loading by the blocking or filling of pores. So, it is thinkable that the support having mesopores richly can be suitable for metal loading in order to avoid severe pore blocking.

MCM-41, a member of the newly discovered mesoporous molecular sieves M41S family, processes a regular hexagonal array of uniform pore openings with a broad spectrum of pore diameters between 15 and $100 \AA \AA^{6-9}$ This means that proper MCM-41 samples can be designed for a specified toxic gas by changing pore diameters. Through the control of preparation conditions, such as a template, a reaction temperature, time, ${ }^{10}$ and $\mathrm{pH}$ value, ${ }^{11}$ high quality MCM-41 materials can be obtained with the properties such as high specific surface area, large pore volume, and ordered pore size. ${ }^{12}$ Moreover, the MCM-41 are mainly composed of $\mathrm{SiO}_{2}$ molecules, indicating that the surface polarity can be high enough to have good chemical affinity with toxic polar gases, such as $\mathrm{NO}_{\mathrm{x}}$ or $\mathrm{SO}_{\mathrm{x}}$.

These materials are promising as catalytic supports for materials such as metal oxides and organometallic compounds because of their large surface area and ordered mesoporous structure. The synthesis of mesoporous catalysts with redox properties is carried out by introducing transition metals such as Ti, $\mathrm{V}, \mathrm{Zr}$, and $\mathrm{Cr}$ in the silica.

Supported $\mathrm{Cu}$ catalysts are known as interesting materials because of the low cost of $\mathrm{Cu}$ and the advantageous catalytic properties of $\mathrm{Cu}$-containing catalysts for various classes of reaction. ${ }^{13}$

The objective of the present work is to investigate the surface properties and textural properties of $\mathrm{Cu} / \mathrm{MCM}-41$, to discuss the NO reduction behaviors of $\mathrm{Cu} / \mathrm{MCM}-41$ with different $\mathrm{Cu}$ content, and to evaluate the possibility of MCM-41 as a filter media for toxic gases.

\section{Experimental}

Sample preparation. To prepare MCM-41, fumed silica was added to cetyltrimethylammonium chloride solution ( $25 \mathrm{wt} \%$, Aldrich) at certain mixing ratio and $\mathrm{pH}$ value of 13 . After drying, the as-synthesized samples were heated in the stream of air for $6 \mathrm{~h}$ at $823 \mathrm{~K}$. For the observation of MCM structures, a TEM was employed. The $\mathrm{Cu} / \mathrm{MCM}-41$ samples were prepared by stirring MCM-41 for $1 \mathrm{~h}$ at room temperature and for $1 \mathrm{~h}$ at $323 \mathrm{~K}$ with $0.023 \mathrm{M}$ solution of $\mathrm{Cu}$ (II) acetylacetonate in chloroform, and then the chloroform was evaporated. A Cu loading was con- 
trolled by using $\mathrm{Cu}(\mathrm{II})$ acetylacetonate solution with initial concentrations of 5, 10, 20, and 40\% and named as 5\%-CM, 10\%CM, 20\%-CM, and 40\%-CM.

Textural properties. Nitrogen adsorption isotherms were measured by using an ASAP 2010 (Micromeritics) at $77 \mathrm{~K}$. Prior to each analysis, the samples were outgased at $573 \mathrm{~K}$ for $12 \mathrm{~h}$ to obtain a residual pressure of less than $10^{-3}$ torr. The amount of nitrogen adsorbed, which was used to calculate specific surface area and pore volume was investigated by BET's equation ${ }^{14}$ and Boer's $t$-plot method. ${ }^{15}$ Total pore volume was estimated to be the liquid volume of nitrogen at a relative pressure of about $0.995 .^{16,17}$

NO reduction test. For the present experiments, a gas chromatograph (DS-6200 model, Donam Co.) with a thermal conductivity detector was used to measure NO conversion of the $\mathrm{Cu} / \mathrm{MCM}-41$. Reactor temperature was sustained constantly at $500{ }^{\circ} \mathrm{C}$ using a PID temperature controller (UP-350, Yokogawa), and the gas flow rate was maintained at $15 \mathrm{~mL} / \mathrm{min}$ by a mass flow controller (GMC 1000, MKS). All samples were heated under a helium purge at $150{ }^{\circ} \mathrm{C}$ for $1 \mathrm{~h}$ to remove residual $\mathrm{H}_{2} \mathrm{O}$ before NO conversion test. The NO conversion was determined from the concentration of $\mathrm{NO}$ at the outlet reactor. Prior to each analysis, NO standard curve was gained by using the 300, 600, and 1000 ppm NO gas.

\section{Results and Discussion}

Microstructures. The small angle XRD patterns of the MCM41 with and without $\mathrm{Cu}$ loading were shown in Figure 1. A major peak at $2 \theta=2^{\circ}(100)$ along with three small peaks was observed due to the (110), (200), and (210) plane reflection lines. ${ }^{6,7}$ These three reflection lines are generally indexed for the hexagonal unit cell as seen in the TEM image. In case of the $\mathrm{Cu} / \mathrm{MCM}-41$ sample, three small peaks mentioned above were not clearly observed. This result indicates that $\mathrm{Cu}$ particles can be intercalated into the hexagonal unit cells and affect the changes of reflection lines, resulting in the decrease of typical MCM-41 peaks.

Surface properties. Figure 2 shows FT-IR spectra of the MCM-41 and $\mathrm{Cu} / \mathrm{MCM}-41$ synthesized. Two strong adsorption bands at 780 and $960 \mathrm{~cm}^{-1}$ suggested that the Si-O-Si and $\mathrm{Si}-\mathrm{OH}$ structures were found. It was also found that the bands at 960 $\mathrm{cm}^{-1}$ and $1000 \sim 1100 \mathrm{~cm}^{-1}$ of the $\mathrm{Cu} / \mathrm{MCM}-41$ decreased with $\mathrm{Cu}$ loading probably due to the incorporation of $\mathrm{Cu}$ particles into the MCM framework. In case of two adsorption bands observed at 1580 and $1630 \mathrm{~cm}^{-1}$, a Cu complex can be localized in the extra-framework position, to give rise to an intense band at $1630 \mathrm{~cm}^{-1}$ and a small one at $1580 \mathrm{~cm}^{-1}$.

Textural properties. Nitrogen adsorption isotherms of the MCM-41 before and after $\mathrm{Cu}$ loading were shown in Figure 3. All of the specimens were approximately the Type IV isotherms showing typical ones according to the IUPAC's classification. ${ }^{16}$ A round knee, which indicated the capillary condensation (mesopore filling), ${ }^{18,19}$ was observed at $\mathrm{P} / \mathrm{P}_{0}=0.29-0.37$ in the isotherm of $\mathrm{Cu} / \mathrm{MCM}-41$ compared to that of the MCM-41 (at P/ $\mathrm{P}_{0}=0.32-0.39$ ). It can be explained that the mesopore distribution was shifted to low relative pressure after $\mathrm{Cu}$ loading, because $\mathrm{Cu}$ particles affected the pore narrowing or blocking of

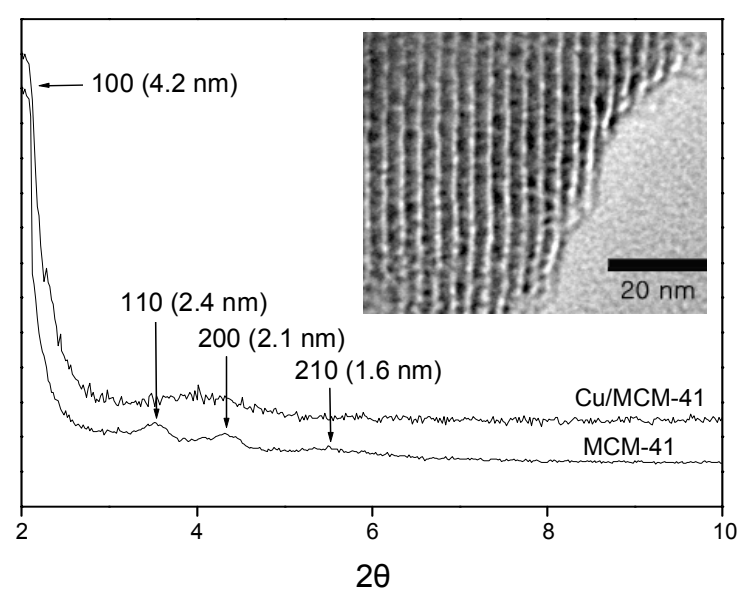

Figure 1. TEM image and small angle XRD patterns of the MCM-41 and $\mathrm{Cu} / \mathrm{MCM}-41$.

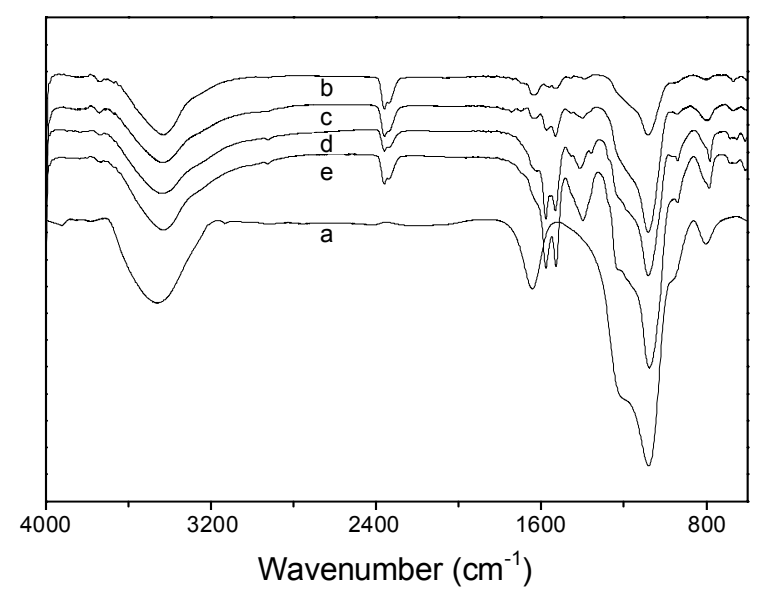

Figure 2. FT-IR spectra of the MCM-41 and $\mathrm{Cu} / \mathrm{MCM}-41$ as a function of Cu content: (a) MCM-41, (b) 5\%-CM, (c) 10\%-CM, (d) 20\%-CM, (e) $40 \%-\mathrm{CM}$.

the mesopores in the MCM-41.

The specific surface areas, pore volumes, total pore volumes, and average pore diameters of the MCM-41 and $\mathrm{Cu} / \mathrm{MCM}-41$ are listed in Table 1. It can be seen that the MCM-41 possesses a high specific surface area of $831 \mathrm{~m}^{2} / \mathrm{g}$ and a large pore volume of $1.034 \mathrm{~cm}^{3} / \mathrm{g}$. Textural properties including the specific surface area and the pore volume are somewhat reduced due to the filling or blocking of pores. In addition, the average pore diameter was decreased slightly with $\mathrm{Cu}$ loading on the MCM-41. This result probably has a close relation with the shifting of mesopore region in Figure 3.

However, these decrease in pore volume after metal loading is much less than that of carbonaceous support. ${ }^{2,3}$ As mentioned in the introduction, carbonaceous support have micropore richly, so severe pore blocking must happen. But MCM-41 supports have mesopore mainly, resulting in remarkably less blocked pore volumes.

Moreover, the pore structure of the MCM-41 is highly ordered like tunnels. This result indicates that NO molecules can be easier to reach active metal surfaces in the tunnel-like pores than that of the active carbons which have complex pore struc- 
Table 1. Textural Properties of the MCM-41 and $\mathrm{Cu} / \mathrm{MCM}-41$ as a Function of Metal Content

\begin{tabular}{lccccc}
\hline & MCM-41 & $5 \%-C M$ & $10 \%-C M$ & $20 \%-C M$ & $40 \%-C M$ \\
\hline Specific surface area $\left(\mathrm{m}^{2} \cdot \mathrm{g}^{-1}\right)$ & 831 & 740 & 670 & 540 & 455 \\
Micropore volume $\left(\mathrm{cm}^{3} \cdot \mathrm{g}^{-1}\right)$ & 0.833 & 0.667 & 0.614 & 0.504 & 0.409 \\
Total pore volume $\left(\mathrm{cm}^{3} \cdot \mathrm{g}^{-1}\right)$ & 1.034 & 0.988 & 0.884 & 0.637 & 0.588 \\
Average pore diameter $(\AA)$ & 26.9 & 26.7 & 26.7 & 26.5 & 26.3 \\
\hline
\end{tabular}

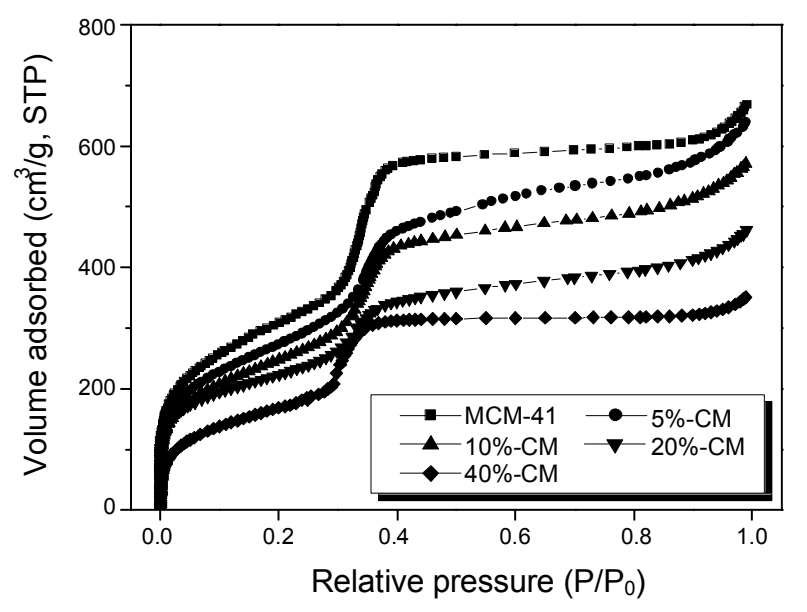

Figure 3. $\mathrm{N}_{2} / 77 \mathrm{~K}$ adsorption isotherms of the $\mathrm{MCM}-41$ and $\mathrm{Cu} / \mathrm{MCM}-$ 41 as a function of $\mathrm{Cu}$ content.

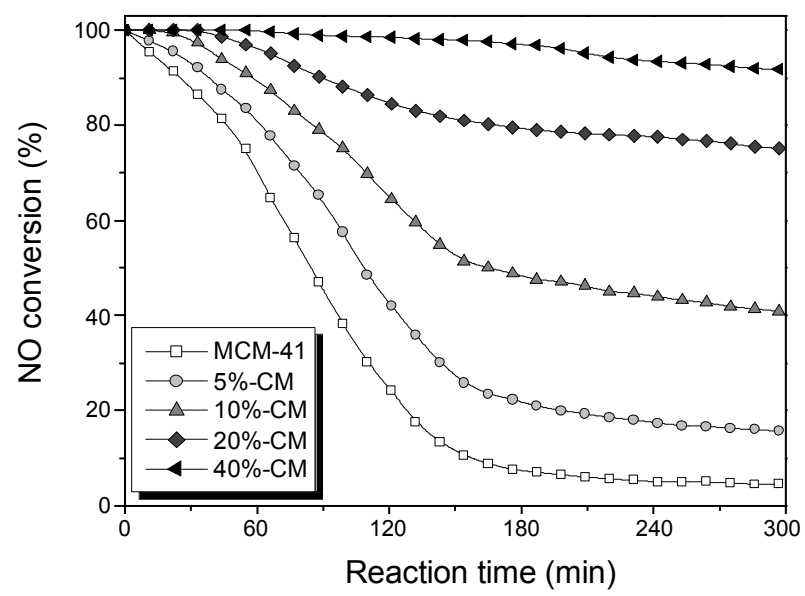

Figure 4. NO conversion by the MCM-41 and $\mathrm{Cu} / \mathrm{MCM}-41$ as a function of $\mathrm{Cu}$ content.

ture. Normally activated carbons have macropores, mesopores, and micropores. The adsorption of NO gas is occurred at mesoand micropores, but the complex pore structures and blocking of pores by metal loading can severely decrease the NO reduction ability of the catalyst. The $\mathrm{Cu} / \mathrm{MCM}-41$ sample in this work can be free of this problem due to its tunnel-like mesopore structure.

NO reduction behaviors. NO reduction behaviors of $\mathrm{Cu}$ supported on the MCM-41 samples measured at $500{ }^{\circ} \mathrm{C}$ were shown in Figure 4. As a result, the MCM-41 sample had low activity, whereas the $\mathrm{Cu} / \mathrm{MCM}-41$ samples had high reduction activity. Also, it could be seen that the NO conversion with the MCM-41 drastically decreased within a few hours, and it reached about $8 \%$ after 100 min on stream. However, the NO removal capacities of the $\mathrm{Cu} / \mathrm{MCM}-41$ at $500{ }^{\circ} \mathrm{C}$ were increased with increasing the $\mathrm{Cu}$ content compared to that of MCM-41. The $\mathrm{Cu} /$ MCM-41 samples showed NO conversions of about 16, 44, 77, and $89 \%$ after $300 \mathrm{~min}$ on stream according to the $\mathrm{Cu}$ contents of $5,10,20$, and $40 \%$, respectively. The capacities of $40 \%-\mathrm{Cu} /$ MCM-41 were kept on removing NO completely for $3 \mathrm{~h}$. Meanwhile, the NO conversion on the MCM-41 was rapidly decreased by $100 \mathrm{~min}$. These results clearly indicated that the $\mathrm{Cu}$ loading was effective method in order to enhance the NO reduction capability of MCM-41.

However, several literatures ${ }^{2,3,5}$ have reported that excessive metal loading normally decreased total reaction sites, resulting the decrease in NO reduction ability of the samples.

According to our previous work, ${ }^{20}$ we revealed that the carbon support didn't chemically adsorb NO gases during the reaction. However, the active metals were oxidized, then were dramatically deoxidized, and finally exhausted $\mathrm{N}_{2}$ and $\mathrm{O}_{2}$ gases as confirmed in a gas chromatography.

Similar reaction can occur in the $\mathrm{Cu} / \mathrm{MCM}-41$ and NO system as equation (1) and (2).

$$
\begin{aligned}
& \mathrm{NO}+\mathrm{Cu} \sim \mathrm{MCM} \rightarrow \mathrm{Cu}_{2} \mathrm{O} \sim \mathrm{MCM}+1 / 2 \mathrm{~N}_{2} \\
& 2 \mathrm{Cu}_{2} \mathrm{O} \sim \mathrm{MCM} \rightarrow 4 \mathrm{Cu} \sim \mathrm{MCM}+\mathrm{O}_{2}
\end{aligned}
$$

So, total reaction can be concluded that NO gases are firstly physic-adsorbed on MCM-41 samples and move to active metal surfaces. And they were chemically reacted and produce $\mathrm{N}_{2}$ and $\mathrm{O}_{2}$ gases on $\mathrm{Cu} / \mathrm{MCM}-41$ surfaces.

\section{Conclusions}

In this work, $\mathrm{NO}$ reduction behaviors of $\mathrm{Cu} / \mathrm{MCM}-41$ were investigated as a function of $\mathrm{Cu}$ content. From the work, the $\mathrm{Cu}$ / MCM-41 samples show NO conversion of about 16, 44, 77, and $89 \%$ after $300 \mathrm{~min}$ on stream according to the various $\mathrm{Cu}$ contents of $5,10,20$, and $40 \%$ though the specific surface areas and the pore volumes of the samples decreased along with the increase of $\mathrm{Cu}$ loading. This result means that the $\mathrm{Cu}$ content on the $\mathrm{Cu} / \mathrm{MCM}-41$ plays an important role in improving the $\mathrm{NO}$ reduction efficiency, due to the reaction between metallic $\mathrm{Cu}$ of the $\mathrm{Cu} / \mathrm{MCM}-41$ and $\mathrm{NO}$ gas.

\section{References}

1. Calvert, S.; Englund, H. M. Handbook of Air Pollution Technology; John Wiley \& Sons: New York, 1984. 
2. Park, S. J.; Kim, B. J. J. Colloid Interface Sci. 2005, 282, 124

3. Park, S. J.; Kim, B. J. J. Colloid Interface Sci. 2005, 292, 493.

4. Kim, B. J.; Lee, Y. S.; Park, S. J. J. Colloid Interface Sci. 2008, 318 , 530.

5. Kim, B. J.; Park, S. J. J. Colloid Interface Sci. 2008, 325, 121

6. Hu, X.; Lei, L.; Chu, H. P.; Yue, P. L. Carbon 1999, 37, 631.

7. Ryoo, R.; Ko, C. H.; Park, I. S. Chem. Commun. 1999, 15, 1413.

8. Kim, J.; Choi, M.; Ryoo, R. Bull. Korean Chem. Soc. 2008, 29, 413.

9. Park, S. J.; Im, S. H. Bull. Korean Chem. Soc. 2008, 29, 777.

10. Chen, Y.; Ciuparu, D.; Lim, S.; Yang, Y.; Haller, G. L.; Pfefferle, L. J. Catal. 2004, 226, 351.

11. Vidya, K.; Gupta, N. M.; Selvam, P. Mater. Res. Bull. 2004, 39, 2035.

12. Zhao, X. S.; Lu, G. Q.; Millar, G. J. Ind. Eng. Chem. Res. 1996, 35, 2075.
13. Hadjiivanov, K.; Tsoncheva, T.; Dimitrov, M.; Minchev, C.; Knozinger, H. Appl. Catal. A: General 2003, 241, 331.

14. Brunauer, S.; Emmett, P. H.; Teller, E. J. Am. Chem. Soc. 1938, 60, 309.

15. de Boer, J. H.; Linsen, B. G.; Plas, T.; Zonder, G. J. J. Catal. 1965, $4,649$.

16. Boehm, H. P. Adv. Catal. 1966, 16, 179.

17. Dubinin, M. M.; Radushkevich, L. V. Doklady Akad. Nauk SSSr. 1947, 55, 331 .

18. Sing, K. S. W.; Everett, D. H.; Haul, R. A. W.; Moscou, L.; Pierotti, R. A.; Rouquol, J.; Siemieniewska, T. Pure Appl. Chem. 1985, 57, 603.

19. Li, Z.; Gao, L. J. Phys. Chem. Solids 2003, 64, 223.

20. Park, S. J.; Jang, Y. S.; Kawasaki, J. Hwahak Konghak 2002, 40, 664. 